were normal but some pupilloconstriction did occur, probably as a result of interruption of sympathetic fibres.

The doll's head and caloric tests, well described by Plum and Posner (1966), may help to locate the brain-stem lesion. Nordgren et al. (1971), like ourselves, usually found conjugate lateral eye movement to be absent both voluntarily and reflexly as judged by the doll's head and caloric tests. This probably results from destruction of the lateral gaze centres on both sides in addition to the ventral pontine damage. Two of our patients, however, displayed tonic abduction of the ipsilateral eye towards the ear irrigated with ice water. This indicates that the medial longitudinal bundle is bilaterally destroyed but that the abducens nucleus is intact. This point is well illustrated in fig. 1, where the area of complete destruction has spared the sixth nerve nucleus and falls just short of the medial longitudinal bundle but is almost certainly impairing its function.

At first sight it is surprising that patients who have such an extensive lesion are not unconscious. A possible explanation (Nordgren et al., 1971) is that so far as the brain stem is concerned consciousness depends on the integrity of the reticular formation in the rostral pons and midbrain, areas which are preserved in the locked-in syndrome. Indeed the E.E.G.s from all our subjects (Hawkes and Bryan-Smyth, 1974) were normal or nearly so, in keeping with their alert state.

The locked-in syndrome is often overlooked and the misdiagnosis of true coma made, probably because of a failure to test voluntary vertical conjugate gaze, which is often the only movement of which such patients are capable. Many were referred to our E.E.G. department as "unexplained coma" but almost all their records were those of wakefulness (Hawkes and Bryan-Smyth, 1974).

In contrast to the series of Nordgren et al. (1971) our patients were distinctly younger (mean age 39 years) and survived longer (mean survival 14 months) whereas their patients were mostly over 60 and died within one week. Despite our longer survival rate the two survivors can hardly be said to have made a worthwhile recovery. Both regained speech and some limb movement but remained confined to a wheelchair.

It has been suggested (Jennett and Plum, 1972) that the terms "locked in," "akinetic mutism," etc., be abandoned and grouped as "persistent vegetative state." Some patients with the latter condition, however, will be conscious and others not, a distinction obviously of clinical importance. Though the term "locked in" is perhaps not ideal it does help to draw attention to the plight of vegetative patients who are aware of their environment and need sympathetic handling.

I wish to thank Dr. G. S. Graveson and Dr. R. O. Weller for their advice in writing this article, and Mr. R. Hunt for technical help. I am also indebted to Dr. P. K. Robinson, Dr. L. S. Illis, Mr. J. Brice, and Mr. J. S. Garfield for permission to write up cases under their care.

\section{References}

Adams, R. D., Victor, M., and Mancall, E. L. (1959). Archives of Neurology and Psychiatry, 81, 154

Chase, T. N., Moretti, L., and Prensky, A. L. (1968). Neurology (Minneapolis), 18, 357.

Progrès Médical, 3, 629.

Hall, J. H., and Karp, H. R. (1973). Neurology (Minneapolis), 23, 6.

Halsey, J. H., and Downie, A. W. (1966). Fournal of Neurology, Neurosurgery and Psychiatry, 29, 350.

Hawkes, C. H., and Bryan-Smyth, L. (1974). Neurology (Minneapolis). In press.

Jennett, B., and Plum, F. (1972). Lancet, 1, 734

Karp, J. S., and Hurtig, H. I. (1974). Archives of Neurology, 30, 176

Nordgren, R. E., et al. (1971). Neurology (Minneapolis), 21, 1140.

Plum, F., and Posner, J. D. (1966). Diagnosis of Stupor and Coma. Philadelphia, Davis.

\title{
Role of Serial Plasma C.E.A. Assays in Detection of Recurrent and Metastatic Colorectal Carcinomas
}

\author{
A. M. MACKAY, S. PATEL, S. CARTER, U. STEVENS, D. J. R. LAURENCE, \\ E. H. COOPER, A. M. NEVILLE
}

British Medical fournal, 1974, 4, 382-385

\section{Summary}

Serial estimations of plasma carcinoembryonic antigen (C.E.A.) levels have been carried out in 220 patients with colorectal carcinomas who had potentially and apparently curative surgery. In a two-year follow-up period 53 patients developed recurrences or metastases. In 36 of these patients sustained rises in plasma C.E.A. titres

Institute of Cancer Research: Royal Cancer Hospital, Chester Beatty Research Institute, London SW3 6JB

A. M. MACKAY, M.D., M.R.C.PATH., Reader in Pathology

S. PATEL, Junior Technician

S. CARTER, Junior Technician

D. JR LAURENCE, PH.D., Senior Scientist

A. M. NEVILLE, M.D., M.R.C.PATH., Professor of Experimental Pathology

Department of Experimental Pathology and Cancer Research, School of Medicine, Leeds LS2 9NL

E. H. COOPER, M.D., F.R.C.P., Professor of Cancer Research occurred synchronously with or between three and 18 months before the clinical detection of recurrences or metastases. The use of serial plasma C.E.A. assays is therefore recommended as an additional diagnostic aid for the earlier detection of recurrent or metastatic colorectal carcinomas.

\section{Introduction}

Previous studies have shown that estimation of the plasma levels of carcinoembryonic antigen (C.E.A.) (Gold and Freedman, 1965) has limited value in the diagnosis or differential diagnosis of localized carcinomas of the colon and rectum (Moore et al., 1971; Holyoke et al., 1972; Laurence et al., 1972; Zamcheck et al., 1972; Mach et al., 1973; Elias et al., 1974; Skarin et al., 1974).

Raised plasma C.E.A. levels, however, occur more frequently once the colorectal carcinomas have spread outside the confines of the bowel and especially with spread to the liver. These values return to normal with apparently complete surgical resection of the tumour. 
These observations suggested that serial assays of plasma C.E.A. during the follow-up phase after surgery might, by showing progressively rising titres, facilitate the detection of recurrent or metastatic disease or both earlier than by clinical methods.

The present investigation was undertaken to assess this possibility and to discover whether preoperative plasma C.E.A. levels might also serve as a prognostic index.

\section{Patients}

Altogether 220 patients were studied. All had had colorectal carcinomas surgically resected and were attending St. Helier and Epsom General Hospitals, Surrey, and hospitals in the West and East Ridings of Yorkshire for follow-up assessment. Of the 142 patients in whom plasma C.E.A. surveillance began postoperatively 23 had their colorectal carcinomas removed before 1970 and 20 during the early part of 1973 . The remaining 99 were operated on during 1970-2.

In 78 of the patients surveillance of the plasma C.E.A. values began preoperatively and was continued thereafter at each outpatient follow-up assessment. In the remaining 142 patients plasma C.E.A. was estimated solely during the postoperative follow-up phase. Hence the period between operation and the first C.E.A. assay was variable.

All the patients satisfied the following criteria. (a) Their operations were considered to be clinically curative. (b) Pathological staging showed the carcinoma to fall into Dukes's (1950) A, B, or C category. (c) The subjects had been followed up for at least 12 months and most for 24 months either after the operation or after the first plasma C.E.A. assay. (d) The plasma C.E.A. level was considered to be normal if it remained consistently below $20 \mathrm{ng} / \mathrm{ml}$ and abnormal if it rose to and remained at levels in excess of $40 \mathrm{ng} / \mathrm{ml}$. These levels were chosen on the basis of our previous experience, which showed that levels over $40 \mathrm{ng} / \mathrm{ml}$ were associated solely with malignant neoplasms, whereas reactive and inflammatory conditions could yield results in the normal range or up to $40 \mathrm{ng} / \mathrm{ml}$ (Laurence et al., 1972).

A further 250 patients under surveillance have been omitted from the present results because of an inadequate follow-up time or because the plasma C.E.A. values had risen temporarily to or remained at levels between 20 and $40 \mathrm{ng} / \mathrm{ml}$. Further study and more time will be required to assess the significance of such levels in that group.

\section{Methods}

The technique for collecting plasma and the double-antibody radioimmunoassay used to measure C.E.A. have been described in detail previously (Laurence et al., 1972). Recurrence of tumour was detected clinically or by radioisotope scanning or other radiographic techniques.

\section{Results}

Altogether 167 patients were considered to be well and to be without clinical evidence of recurrent disease (table I). In 150 of

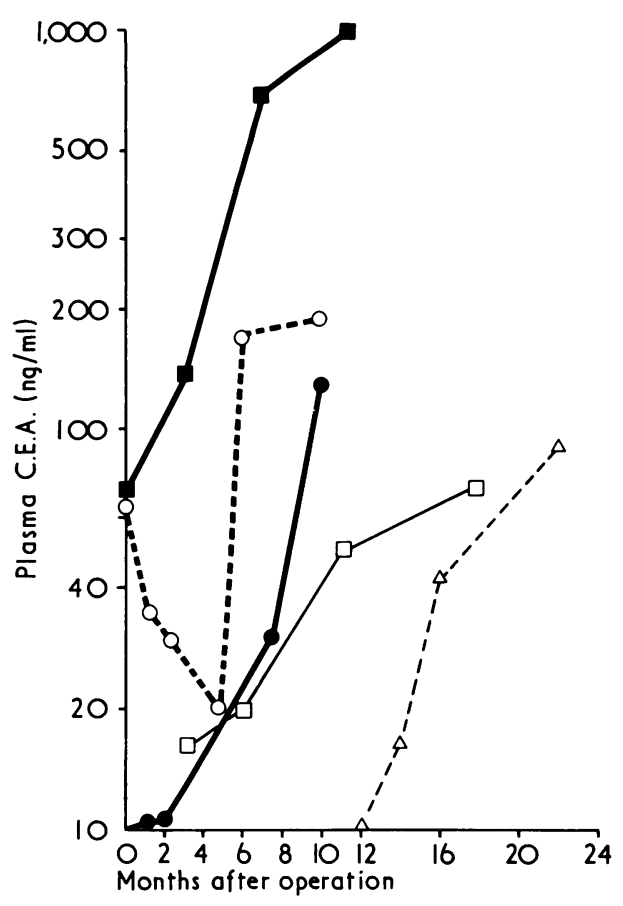

FIG. 1-Serial changes in plasma C.E.A. levels in five patients. Time 0 refers to day before or of operation. In none is there clinical evidence of recurrent or metastatic disease at this time. Raised preoperative level in case 1 ( $\square-0)$ failed to return to normal after operation and rose progressively. Though levels fell again after operation in case $2\left(\mathrm{O}_{-}-\mathrm{O}\right)$ steady rise occurred thereafter; similar trends are shown in case 3 (-) though preoperative level was normal. In cases 4 and $5(\square-\square ; \triangle--\triangle)$ normal C.E.A. titres were found at first postoperative analysis but rising levels were recorded later.

these the plasma C.E.A. levels remained in the normal range throughout the assessment period. In the remaining 17 progressively rising titres exceeding $40 \mathrm{ng} / \mathrm{ml}$ were observed. Representative trends of plasma C.E.A. levels are shown in fig. 1.

Fifty-three patients developed either recurrent or metastatic tumours or both during the assessment period (table I); in 26 clinical detection of the recurrent tumours was preceded by plasma C.E.A. titres rising to pathological levels $(>40 \mathrm{ng} / \mathrm{ml})$. Examples of the rate of this change in plasma C.E.A. levels are shown in fig. 2. In a further 10 patients rising titres were noted synchronously with the clinical detection of the tumour. In 17 patients no change in C.E.A. levels occurred in association with the clinical re-establishment of recurrent or metastatic tumour.

\section{TEMPO OF CHANGES IN PLASMA C.E.A.}

The interval between the occurrence of levels of plasma C.E.A. in excess of $40 \mathrm{ng} / \mathrm{ml}$ and the clinical detection of recurrent or metastatic disease or both in the 26 patients is shown in table II. A lead time of about nine months was most commonly achieved though up to 18 months was noted in one instance. The time when such changes begin and their rate of evolution in relation to the site of the subsequent metastases are shown in fig. 2 . The

TABLE I-Changes in Plasma C.E.A. Levels in 220 Patients with and without Evidence of Recurrence after Resection of Colorectal Carcinomas

\begin{tabular}{|c|c|c|c|c|}
\hline \multirow{2}{*}{ Clinical Status } & \multirow{2}{*}{ Plasma C.E.A. } & \multicolumn{3}{|c|}{ No. of Patients } \\
\hline & & Preoperative Group & Follow-up Group & Total \\
\hline $\begin{array}{l}\text { Well, no evidence of recurrence } \\
\text { Recurrence }\end{array}$ & $\begin{array}{l}\text { Normal } \\
\text { Rising }(>40 \mathrm{ng} / \mathrm{ml}) \\
\text { Unchanged } \\
\text { Synchronous rise to }>40 \mathrm{ng} / \mathrm{ml}^{*} \\
\text { Preceded by rise to }>40 \mathrm{ng} / \mathrm{ml}\end{array}$ & $\begin{array}{r}45 \\
10 \\
6 \\
3 \\
14\end{array}$ & $\begin{array}{r}105 \\
7 \\
11 \\
7 \\
12\end{array}$ & $\left.\begin{array}{r}150 \\
17 \\
17 \\
10 \\
26\end{array}\right\} 53$ \\
\hline Total & & 78 & 142 & 220 \\
\hline
\end{tabular}

*Recurrence was detected clinically at time rise in plasma C.E.A. was noted. 
failure of preoperative levels to return to normal in the immediate postoperative period tended to be associated with a subsequent rapid rise and the earlier detection of metastases.

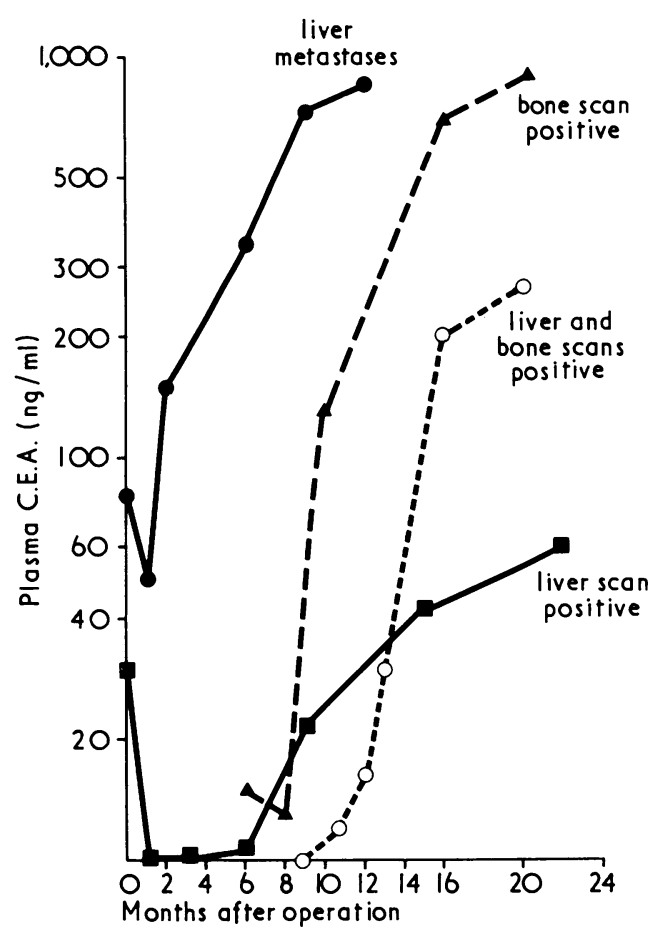

FIG. 2-Serial change in plasma C.E.A. levels before clinical detection of recurrence in four patients. Time 0 refers to day before or of operation. Last recorded C.E.A values shown coincide with clinical detection of metastatic disease. In case 1 (ues diter occurred postoperatively, while in case $2(\square-\square)$ values returned initially to normal for during postoperative phase and then rising levels were observed.

TABLE II-Lead Time Given by Plasma C.E.A. Assay over Clinical Detection of Recurrent and/or Metastatic Colorectal Carcinomas

\begin{tabular}{lll|r|r|r|r|r|r|c}
\hline Time in months & $\ldots$ & $\ldots$ & -3 & -6 & -9 & -12 & -15 & -18 & Total \\
No. of patients &. &. & 1 & 7 & 12 & 4 & 1 & 1 & 26
\end{tabular}

TABLE III-Changes in Plasma C.E.A. as Function of Metastatic Site. Figures are Numbers of Patients

\begin{tabular}{l|c|c|c}
\hline \multirow{2}{*}{ Metastatic Site } & \multicolumn{3}{|c}{ Change in Plasma C.E.A. } \\
\cline { 2 - 4 } & None & $\begin{array}{c}\text { Synchronous } \\
\text { Rise }\end{array}$ & $\begin{array}{c}\text { Preceded by } \\
\text { Rise }\end{array}$ \\
\hline Liver & 7 & 7 & 17 \\
Lung & 1 & 1 \\
Beritoneum and pelvis & 7 & 5 & 5 \\
Local & 4 & 1 & 1 \\
Skin & 2 & & \\
\hline
\end{tabular}

\section{SITE OF METASTASES}

The site of the metastases tended to influence whether raised plasma C.E.A. values would develop or not (table III). Most but not all of the subjects with hepatic secondary tumours had raised levels. In those with normal values and secondary deposits in the liver continued assessment showed the values to rise subsequently to pathological levels. Raised C.E.A. values were less likely to be observed with pelvic and peritoneal metastases and were highly unlikely with local recurrences. In these cases the volume of tumour tended to be less than that present in metastatic liver disease.

\section{C.E.A. LEVELS AND PROGNOSIS}

The changes in plasma levels of C.E.A. occurring after operation were analysed in the 78 patients in whom preoperative C.E.A. levels were known to ascertain whether a particular pattern of change is more likely to be associated with recurrent tumour development (table IV). No recurrences or metastases had been detected at the time of writing in the 18 patients with raised preoperative values which returned to and remained normal after operation. By contrast seven out of nine patients developed recurrent or metastatic tumours when the plasma C.E.A. failed to return to normal in the immediate postoperative period. No particular tumour characteristics are known to identify those lesions which will on recurrence be associated with normal or raised C.E.A. levels when the preoperative levels were normal.

The precise preoperative C.E.A. level in plasma did not appear to act as a clear prognostic index with regard either to the incidence of recurrences (table V) or to the free interval before their detection (table VI). Dukes's staging seemed to remain a more accurate index. Within any particular Dukes's stage, however, there was a tendency for the higher plasma values to carry a worse prognosis. Of apparently greater importance was the postoperative sequence of change in plasma C.E.A. levels; failure to return to normal indicated spread outside the apparent pathological stage and a high and early rate of recurrence (tables V and VI).

TABLE v-Prognostic Value of Preoperative Plasma C.E.A. Levels as Function of Pathological Classification. Results Expressed as Number of Patients

\begin{tabular}{c|c|c|c|c}
\hline \multirow{2}{*}{$\begin{array}{c}\text { Preoperative Plasma C.E.A. } \\
\text { Levels (ng/ml) }\end{array}$} & \multicolumn{2}{|c|}{ Pathological Classification* } & \multirow{2}{*}{ Total } \\
\cline { 2 - 4 } & A & B & C & \\
\hline 20 & $0 / 7$ & $5 / 18$ & $7 / 17$ & $12 / 42$ \\
$20-40$ & $0 / 5$ & $2 / 5$ & $2 / 5$ & $4 / 15$ \\
$>40$ & $0 / 1$ & $2 / 3 \dagger$ & $5 / 7 \dagger$ & $7 / 11$ \\
\hline Total & $0 / 13$ & $9 / 26$ & $14 / 29$ & $23 / 68$ \\
\hline
\end{tabular}

*Dukes (1950)

†Levels did not return to normal postoperatively.

\section{Discussion}

Since the initial observations that increased plasma C.E.A. titres were in part stage-dependent (Laurence et al., 1972;

TABLE IV-Incidence of Recurrence or Metastases in Relation to Changing Levels of Plasma C.E.A.

\begin{tabular}{|c|c|c|c|c|}
\hline \multicolumn{3}{|c|}{ Plasma C.E.A. Levels } & \multirow{2}{*}{$\begin{array}{l}\text { No. of Patients with } \\
\text { Overt Recurrences } \\
\text { or Metastases }\end{array}$} & \multirow{2}{*}{ Total } \\
\hline Before Operation & One Month after Operation & At Subsequent Follow-up & & \\
\hline $\begin{array}{l}\text { Normal } \\
\text { Raised } \\
\text { Normal } \\
\text { Raised } \\
\text { Raised }\end{array}$ & $\begin{array}{l}\text { Normal } \\
\text { Normal } \\
\text { Normal } \\
\text { Normal } \\
\text { Remained raised }\end{array}$ & $\begin{array}{l}\text { Normal } \\
\text { Normal } \\
\text { Rising* } \\
\text { Rising* } \\
\text { Rising further* }\end{array}$ & $\begin{array}{l}\mathbf{4} \\
0 \\
8 \\
4 \dagger \\
7\end{array}$ & $\begin{array}{r}31 \\
18 \\
11 \\
9 \\
9\end{array}$ \\
\hline Total & & & 23 & 78 \\
\hline
\end{tabular}


TABLE VI-Prognostic Value of Preoperative Plasma C.E.A. Levels as Function of Time to Recurrence. Results Expressed as Number of Patients

Preoperative Plasma C.E.A. Levels $(\mathrm{ng} / \mathrm{ml})$

$$
\text { Pathological Classification }
$$

\begin{tabular}{|c|c|c|c|c|c|c|c|c|}
\hline \multirow{2}{*}{ Postoperative time (months) to recurrence: } & \multicolumn{4}{|c|}{ B } & \multicolumn{4}{|c|}{ C } \\
\hline & Under 6 & -12 & -18 & Over 18 & Under 6 & -12 & -18 & Over 18 \\
\hline $\begin{array}{l}<20 \\
20-40 \\
>40\end{array}$ & 1 & $\begin{array}{l}2 \\
2 \\
2\end{array}$ & 1 & 1 & $\begin{array}{l}1 \\
2\end{array}$ & $\begin{array}{l}4 \\
2\end{array}$ & $\begin{array}{l}2 \\
1\end{array}$ & $\begin{array}{l}1 \\
1\end{array}$ \\
\hline Total & 1 & 6 & 1 & 1 & 3 & 6 & 3 & 2 \\
\hline
\end{tabular}

Mach et al., 1973) attention has focused on the potential role of plasma C.E.A. surveillance as a method to facilitate the earlier detection of recurrent or metastatic colorectal carcinomas in the postoperative follow-up period. Preliminary reports have given grounds for cautious optimism (Neville and Laurence, 1974; Sorokin et al., 1974).

In the present series three patterns in the level of plasma C.E.A. were observed-namely, progressively rising or sustained high levels $(>40 \mathrm{ng} / \mathrm{ml}$ ), transient increases, and continuously normal values $(<20 \mathrm{ng} / \mathrm{ml})$. As yet no recurrence has been found in any patient with a transient rise; the significance of this is the subject of further study.

A C.E.A. level in excess of $40 \mathrm{ng} / \mathrm{ml}$ was chosen as truly abnormal because levels between 20 and $40 \mathrm{ng} / \mathrm{ml}$ can occur and seldom exceed $40 \mathrm{ng} / \mathrm{ml}$ in association with a variety of non-neoplastic inflammatory and regenerative disorders (Laurence et al., 1972).

With the use of these criteria raised plasma levels of C.E.A. were detected in 36 of the 53 subjects in whom recurrences became clinically overt. In 26 of these patients the plasma levels became raised and rose further for between three and 18 months before the detection of the recurrent or metastatic disease. These trends in plasma C.E.A. levels in subjects with confirmed metastatic disease may allow us to conclude that the other 17 subjects with values in excess of $40 \mathrm{ng} / \mathrm{ml}$ though apparently clinically well also had latent tumours (table I).

Consequently it may be calculated from this information that $76 \%$ of patients-that is, 53 out of 70 -will develop rises in plasma C.E.A. levels irrespective of the preoperative level synchronously with the development of recurrent or metastatic disease but usually before it becomes overt. Therefore at present the serial assay of plasma C.E.A. represents an important addition to the armamentarium available to the clinician for the detection of recurrent and metastatic tumours of colorectal origin and its use as a screening procedure during the postoperative follow-up phase is to be recommended.

The availability to the clinician of this type of informationnamely, that recurrent disease may already be present-may provide justification for "second-look" surgery (Wangensteen et al., 1954) or the institution of chemotherapeutic or radiotherapeutic procedures or both at an earlier phase in the progression of the disease. Whether this will result in improved survival is unknown.

Most patients in the present series had plasma C.E.A. values continuously in the normal range (tables I and IV). As this does not preclude the presence of tumour and its subsequent overt recurrence, however, there is a need to evolve further methods which will help to ascertain beforehand which tumours will recur with normal plasma C.E.A. levels and which will be associated with raised levels. While the site of the metastases and the volume of tumour may be important (table III) table IV shows that when preoperative levels were raised recurrence was also associated with high levels.

Functional methods of examining primary tumours associated with normal preoperative plasma levels for the presence or absence in the tumour of C.E.A. may be of value and seem worth further study. The direct extraction and assay of the tumours for C.E.A., the use of immunoperoxidase staining techniques for its localization in or on cells, or the establishment of the tumours in organ and monolayer cultures (Breborowicz et al., 1973) to detect whether they can produce and release C.E.A. into the medium seem appropriate ancillary investigations which the pathology laboratory could undertake.

As noted above we have excluded from the present series a number of other patients being followed up after operation as their plasma C.E.A. values had risen from normal to between 20 and $40 \mathrm{ng} / \mathrm{ml}$. While this value may eventually be used to indicate at an even earlier stage the presence of recurrent tumour further time is needed to ascertain or refute this conclusion. The concomitant measurement of other tumour associated antigens such as AFP (Thompson et al., 1974) or serum enzymes such as $\gamma$-glutamyl transpeptidase $(\gamma \mathrm{GT})$ (Steele et al., 1974) may help to clarify the situation, particularly when liver metastases are suspected. Preliminary data to be reported in detail elsewhere indicate that about $50 \%$ of this group with C.E.A. values between 20 and $40 \mathrm{ng} / \mathrm{ml}$ also had raised $\gamma$-GT serum levels (Cooper et al., 1974).

Chu (1974) presented tentative evidence which suggests that the preoperative level of plasma C.E.A. might act as a prognostic index. Tumours associated with high levels were reported to recur earlier. We cannot confirm this at present; neither can it be refuted (tables $\mathrm{V}$ and VI). Our data tend to suggest that the level of preoperative C.E.A. may be a function of the existence of wider dissemination of tumour than can be detected at operation (tables V and VI) (Laurence et al., 1972).

We wish to express our appreciation to our clinical colleagues Professor J. C. Goligher and Messrs. O. Davies, R. Hall, D. Johnston, A. MacAdam, and A. York Mason, who kindly made clinical material available, to Dr. C. W. Todd for his continuing interest and the supply of suitable reagents, and to Dr. R. Bettelheim, Mrs. M. Woollard, and Miss S. Clowe for their collection and documentation of the material and results.

This work was supported by the Medical Research Council (Grant G971/817/B).

\section{References}

Breborowicz, J., Easty, G. C., and Neville, A. M. (1973). Lancet, 2, 1393.

Chu, T. M. (1974). Quoted by Neville and Laurence (1974).

Cooper, E. H., et al. (1974). British fournal of Cancer. In press.

Dukes, C. E. (1950). British fournal of Cancer, 4, 59.

Elias, E. G., Holyoke, E. D., and Chu, T. M. (1974). Diseases of the Colon and Rectum, 17, 38.

Gold, P., and Freedman, S. O. (1965). Fournal of Experimental Medicine, 122, 467.

Holyoke, D., Reynoso, G., and Chu, T. M. (1972). Annals of Surgery, 176, 559.

Laurence, D. J. R., et al. (1972). British Medical fournal, 3, 605. Mach, J.-P., et al. (1973). Schweizerische medizinische Wochenschrift, 103, Moore, T. L., Kupchik, H. Z.,
Digestive Diseases, 16, 1 .

Digestive Diseases, 16, 1.
Neville, A. M., and Laurence, D. J. R. (1974). International fournal of Cancer, 14, 1.

Skarin, A. T., et al. (1974). Cancer Philadelphia, 33, 1239.

Sorokin, J. J., et al. (1974). Fournal of the American Medical Association, 228, 49.

Steele, L., ot al. (1974). British fournal of Cancer. In press.

Thompson, W. G., et al. (1974). Canadian Medical Association fournal, 110, 775.

Wangensteen, O. H., Lewis, F. J., and Arbelger, S. W. (1954). Surgery, Gynecology and Obstetrics, 99, 257.

Zamcheck, N., et al. (1972). New England fournal of Medicine, 286, 83. 